\title{
CARACTERIZAÇÃO ANATÔMICA DA MADEIRA DE SIPHONEUGENA REITZII D. LEGRAND (MYRTACEAE) ${ }^{1}$
}

\author{
SIDINEI RODRIGUES DOS SANTOS ${ }^{2}$ JOSÉ NEWTON CARDOSO MARCHIORI $^{3}$
}

\section{RESUMO}

No presente estudo, a estrutura anatômica da madeira de Siphoneugena reitzii D. Legrand é descrita e ilustrada, com base em material proveniente do Rio Grande do Sul, Brasil. Os caracteres anatômicos observados são de ocorrência geral em Myrtoideae, corroborando a homogeneidade estrutural da subfamília. O material descrito distingue-se de outras Mirtoídeas nativas no Estado, principalmente pela altura das séries de parênquima axial e das margens unisseriadas de raios.

Palavras-chave: Siphoneugena, Siphoneugena reitzii, anatomia da madeira, Myrtaceae.

\section{ABSTRACT}

[Wood anatomy of Siphoneugena reitzii D. Legrand (Myrtaceae)].

The wood anatomy of Siphoneugena reitzii D. Legrand is described and illustrated, based on samples from Rio Grande do Sul state, Brazil. The anatomical features observed in the wood are of common occurrence in Myrtoideae, corroborating the structural homogeneity of this subfamily. The described species distinguishes itself from other native Myrtoideae from Rio Grande do Sul state, mainly by the height of parenchyma series and ray margins (unisseriate ends).

Key words: Siphoneugena, Siphoneugena reitzii, wood anatomy, Myrtaceae.

\section{INTRODUÇÃO}

Pouco conhecido, o gênero americano Siphoneugena $\mathrm{O}$. Berg é um dos menores de Myrtaceae, contando com apenas 8 espécies, distribuídas desde Porto Rico até o Norte da Argentina e Brasil (Proença, 1990). Uma nova espécie do sudeste brasileiro, Siphoneugena delicata Sobral \& Proença foi recentemente incluída por Sobral (2006), confirmando esta região como o centro de diversidade do grupo. Um aspecto digno de nota é a preferência da maioria das espécies por ambientes úmidos e montanhosos, caso do material em estudo.

1 Recebido para publicação em 16-3-2010 e aceito para publicação em 21-6-2010.

2 Biólogo, bolsista do CNPq - Brasil, doutorando do Programa de Pós-Graduação em Engenharia Florestal, Departamento de Ciências Florestais, Universidade Federal de Santa Maria. CEP 97105-900. Santa Maria, RS, Brasil. sthurt.bio@gmail.com

3 Engenheiro Florestal, Dr., bolsista de Produtividade em Pesquisa do CNPq, Professor Titular do Departamento de Ciências Florestais, Universidade Federal de Santa Maria, Santa Maria, RS, Brasil.balduinia@mail.ufsm.br
Apesar da proximidade com o centro de dispersão do gênero, o Rio Grande do Sul conta com apenas um representante na flora nativa: Siphoneugena reitzii D. Legrand (Sobral. 2003). Espécie heliófila e seletiva higrófila, a espécie em estudo é um dos elementos mais característicos das florestas Nebular e Ombrófila Mista do nordeste gaúcho (Marchiori \& Sobral, 1997); sua distribuição geográfica, todavia, inclui o restante da região sul, alcançando o estado de São Paulo (Proença, 1990).

Árvore de até $15 \mathrm{~m}$ de altura, de casca lisa e esfoliante, acinzentada ou amarelada (Sobral, 2003), Siphoneugena reitzii apresenta copa arredondada e muito densa, com ramos tortuosos, achatado-tetrágonos quando jovens (Marchiori \& Sobral, 1997). As folhas, curto-pecioladas (1$2 \mathrm{~mm}$ ) e pequenas (15-40 x 5-10 mm), são glabras e discolores. As flores, em número de 2-6 (Sobral, 2003), reúnem-se em pequenos racemos axilares e apresentam hipanto mais longo do que o ovário, afunilado em direção ao ápice, à semelhança de um sifão, como sugere o nome genérico (Marchiori \& Sobral, 1997). 
Conhecida regionalmente como "camboim", a espécie produz madeira muito dura e pesada, utilizada localmente em moirões de cerca ou como lenha (Legrand \& Klein, 1977). A composição e organização da estrutura anatômica da madeira, objetivo do presente estudo, são ainda desconhecidas.

\section{REVISÃO DE LITERATURA}

Com exceção de Siphoneugena densiflora, descrita em conjunto com outras 11 espécies das matas ciliares do centro-oeste brasileiro (Paula et al., 2000), não constam referências anatômicas na literatura consultada sobre os representantes do gênero, nem mesmo em obras clássicas, como Record \& Hess (1949) e Metcalfe \& Chalk (1972).

Para Siphoneugena densiflora, são mencionados os seguintes aspectos anatômicos: porosidade difusa; poros solitários, com 81-103 $\mu \mathrm{m}$ de diâmetro e frequiência de $13-18 / \mathrm{mm}^{2}$; elementos vasculares de $346 \mu \mathrm{m}$ de comprimento, com placas de perfuração simples (raro múltiplas) e pontoações intervasculares alternas; parênquima apotraqueal sub-agregado, além de paratraqueal; raios predominantemente 1-2 seriados, heterogêneos, de células quadradas e procumbentes, com $520 \mu \mathrm{m}$ de altura e freqüência de 5-10/mm; e fibras de 1110 a $1212 \mu \mathrm{m}$ de comprimento.

Na maioria das Mirtoídeas sul-riograndenses descritas por Marchiori (1984a,b,c; 1987; 1988; 1998), Marchiori \& Muñiz (1987), Marchiori \& Brum (1997) e Denardi \& Marchiori (2005), foram observados: poros exclusivamente solitários; porosidade difusa; placas de perfuração simples; pontoações intervasculares alternas e ornamentadas; fibras com pontoações areoladas (fibrotraqueídeos); parênquima apotraqueal difuso e difuso-emagregados; e raios heterogêneos, estreitos. Fibras com pontoações simples ou indistintamente areoladas e porosidade semi-difusa, todavia, foram observadas em Eugenia involucrata e Myrciaria tenella, respectivamente. Placas de perfuração escalariformes constam apenas para Myrceugenia glaucescens. Espessamentos espiralados foram assinalados para Campomanesia guazumaefolia, Eugenia involucrata, Myrceugenia myrtoides, Myrceugenia glaucescens e Myrrhinium atropurpureum. Traqueídeos vasicêntricos foram referidos para Myrceugenia glaucescens, Acca sellowiana, Eugenia involucrata e Myrrhinium atropurpureum. Séries cristalíferas, por sua vez, foram descritas para o parênquima axial de Blepharocalyx salicifolius, Eugenia involucrata, Acca sellowiana e Myrrhinium atropurpureum.

O comprimento e largura de vasos, na maioria das Mirtoídeas nativas, situa-se entre 503$595 \mu \mathrm{m}$ e $42-58 \mu \mathrm{m}$, respectivamente. Muito variável (11-266 poros $\left./ \mathrm{mm}^{2}\right)$, a freqüência de poros é geralmente superior a $50 / \mathrm{mm}^{2}$. A altura das séries parenquimáticas varia de 3 a 8 células, embora em certas espécies, como Blepharocalyx salicifolius (até 12 células), o caráter ultrapassa o referido limite. Os raios têm 1-3, raro 4 células de largura. Quanto à altura, os unisseriados geralmente apresentam-se com 1-10 e os multisseriados 6-25 células, não ultrapassando, em ambos os casos, $500 \mu \mathrm{m}$ de altura. A freqüência de raios, na maioria das espécies, fica entre 15 e $25 / \mathrm{mm}$. O comprimento de fibras, por sua vez, varia de 800 a $1200 \mu \mathrm{m}$, na maioria das espécies.

\section{MATERIAL E MÉTODOS}

O material analisado é proveniente da Floresta Nacional (FLONA) de São Francisco de Paula, Rio Grande do Sul. A amostra de madeira e respectivo material botânico foram incorporados à Xiloteca e Herbário do Departamento de Ciências Florestais (HDCF) da Universidade Federal de Santa Maria, com o número 6140.

Do material lenhoso foram extraídos três corpos de prova $(3 \times 3 \times 3 \mathrm{~cm})$ da parte mais externa do lenho, próxima ao câmbio, orientados para obtenção de cortes nos planos transversal, 
longitudinal radial e longitudinal tangencial. Um outro bloquinho foi também retirado, com vistas à maceração.

Os corpos de prova foram amolecidos por fervura em água e seccionados em micrótomo de deslizamento, regulado para a obtenção de cortes anatômicos com espessura nominal de 20 $\mu \mathrm{m}$. Os cortes foram tingidos com acridina-vermelha, crisoidina e azul-de-astra (Dujardin, 1964), desidratados em série alcoólica-ascendente $(30 \%, 50 \%, 70 \%, 95 \%$ e duas vezes em álcool absoluto), diafanizados em xilol e montados em lâminas permanentes, usando-se Entellan como meio de montagem.

Para as lâminas de macerado, adotou-se o método de Franklin, modificado (Kraus \& Arduin, 1997), usando-se coloração da pasta com safranina $1 \%$ e montagem em lâminas permanentes, com Entellan.

A descrição microscópica da madeira baseou-se nas recomendações do IAWA Committee (1989). No caso da percentagem dos tecidos, foram realizadas 600 determinações ao acaso, com auxílio de contador de laboratório, conforme proposto por Marchiori (1980). A freqüência de poros foi obtida de forma indireta, a partir de um quadrado de área conhecida superposto a fotomicrografias em seção transversal da madeira. As medições foram realizadas em microscópio Carl Zeiss, com ocular de escala graduada, no Laboratório de Anatomia da Madeira da Universidade Federal de Santa Maria. Nas características quantitativas, os números entre parênteses equivalem aos valores mínimos e máximos observados. $\mathrm{O}$ valor que acompanha a média é o desvio padrão. As fotomicrografias foram tomadas em microscópio Olympus cx40, equipado com câmera digital Olympus Camedia c3000.

\section{DESCRIÇÃO ANATÔMICA}

Anéis de crescimento: distintos, delimitados por fina camada de fibras radialmente estreitas (Figura 1B).

Vasos: extremamente numerosos $(131 \pm 12$ $(119-150)$ poros $\left./ \mathrm{mm}^{2}\right)$, ocupando $19 \pm 3 \%$ do volume da madeira. Conteúdo de cor alaranjada, muito escasso. Porosidade difusa (Figura 1A). Poros exclusivamente solitários, ligeiramente poligonais, muito pequenos $(36 \pm 6,4(25-47,5)$ $\mu \mathrm{m})$, de paredes finas $(2,6 \pm 0,4(2,5-3,7) \mu \mathrm{m})$ e sem padrão definido de organização (Figura $1 \mathrm{~A}, \mathrm{~B})$. Elementos vasculares de comprimento médio $(407 \pm 72(280-630) \mu \mathrm{m})$, com placas de perfuração simples, geralmente oblíquas, e apêndices geralmente em ambas as extremidades (Figura 1D). Espessamentos espiralados, ausentes. Pontoações intervasculares alternas, circulares $(3,9 \pm 0,4(3-4,6) \mu \mathrm{m})$, com abertura em fenda inclusa, ornamentada, ao menos em parte dos vasos. Pontoações raio-vasculares com bordas distintas, semelhantes às intervasculares, embora menores $(2,6 \pm 0,4(2,1-3,1) \mu \mathrm{m}) \mathrm{e}$ restritas às células marginais de raios (Figura 1D).

Parênquima axial: muito distinto das fibras em seção transversal, ocupando $20 \pm 3,4 \%$ do volume da madeira, disposto em arranjo apotraqueal difuso e, principalmente, difuso-emagregados, além de paratraqueal escasso (Figura $1 \mathrm{~A}, \mathrm{~B})$. Séries parenquimáticas com $287 \pm 60$ $(210-400) \mu \mathrm{m}$ de altura e $2-4$ células (Figura $1 \mathrm{~F})$.

Raios: muito numerosos $(22 \pm 1(20-24$ raios $/ \mathrm{mm}$ ), com 1 - 3 células de largura, ocupando $19 \pm 3 \%$ do volume da madeira (Figura 1E,F). Raios multisseriados com $193 \pm 64(100$ -330 ) $\mu \mathrm{m}$ de altura e $5-15$, mais comumente 8 - 11 células; heterogêneos, reúnem células procumbentes na parte multisseriada e $1-4$ (6) fileiras marginais de células eretas, quadradas e procumbentes, estas, todavia, maiores do que as do corpo central (Figura 1C,D). A parte multisseriada é geralmente mais longa do que as margens (Figura1E,F). Os unisseriados, com $113 \pm 58(40-280) \mu \mathrm{m} \mathrm{e} 1-6$ células de altura. Raios axialmente fusionados, frequientes. Células radiais de paredes disjuntas, presentes. Raios agregados, células envolventes, células perfuradas e conteúdo, ausentes.

Fibras: de pontoações distintamente areoladas, nas faces radiais e tangenciais da parede. O conjunto do tecido representa $42 \pm 5 \%$ do 

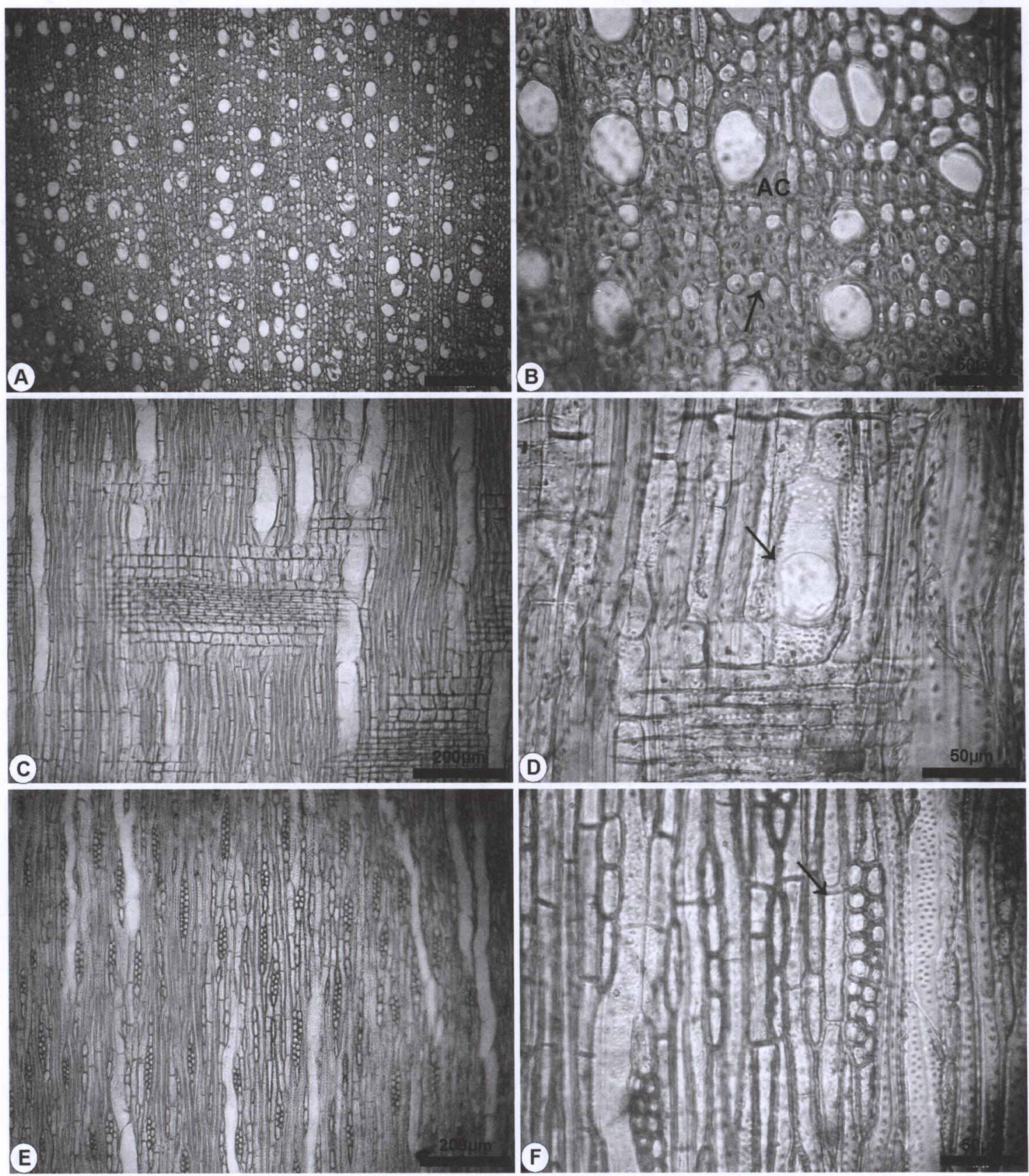

FIGURA 1 - Fotomicrografias da madeira de Siphoneugena reitzii. A - Seção transversal, mostrando porosidade difusa, poros exclusivamente solitários e parênquima apotraqueal difuso-em-agregados. B - Mesma seção, em maior aumento, com destaque para o limite de anel de crescimento (ac), fibras de paredes finas a espessas e parênquima predominantemente difuso-em-agregados (seta). C - Aspecto geral de raio heterogêneo, com células procumbentes, no corpo central, e margens de células curtamente procumbentes, quadradas e eretas (seção longitudinal radial). D - Detalhe da seção radial, mostrando vaso com placa de perfuração simples (seta) e raio heterogêneo. E - Raios com 1-3 células de largura, e margens geralmente mais curtas do que o corpo central (seção longitudinal tangencial). F - Mesma seção, em maior aumento, com destaque para série de parênquima axial (seta), raios uni e bisseriados e fibrotraqueídeos. 
volume da madeira. Fibras de comprimento médio $(1023 \pm 91(860-1180) \mu \mathrm{m})$, com $17 \pm$ $1,7(15-20) \mu \mathrm{m}$ de largura e de paredes finas a espessas $(4,6 \pm 0,56(3,7-5,6) \mu \mathrm{m})$ (Figura 1B). Fibras septadas, fibras gelatinosas e espessamentos espiralados, ausentes. Traqueídeos vasicêntricos, presentes.

Outros caracteres: Variantes cambiais, tubos laticíferos e taniníferos, canais intercelulares, células oleíferas ou mucilaginosas, estratificação e cristais, ausentes. Máculas medulares, ocasionais.

\section{ANÁLISE DA ESTRUTURA ANATÔMICA}

As características anatômicas da madeira de Siphoneugena reitzii corroboram as observações gerais de Record \& Hess (1949), Metcalfe \& Chalk (1972) e Vliet \& Baas (1984) para a família Myrtaceae e subfamília Myrtoideae.

A homogeneidade estrutural das espécies de Myrtoideae, salientada por Dias-Leme et al. (1995) e Détienne \& Jacquet (1983, apud Soffiatti \& Angyalossy-Alfonso, 1999), é reforçada, no presente estudo, pelo grande número de caracteres de ocorrência generalizada neste grupo: porosidade difusa; poros solitários; elementos vasculares de comprimento médio; placas de perfuração simples; pontoações intervasculares ornamentadas; parênquima predominantemente apotraqueal difuso-em-agregados; raios heterogêneos, estreitos; fibras de comprimento médio, com pontoações areoladas; e traqueídeos vasicêntricos.

Comparado a Siphoneugena densiflora, descrita por Paula et al. (2000), destacam-se diferenças no tocante à natureza das placas de perfuração e a certas características quantitativas. Os autores referem a presença de placas escalariformes, caráter não observado no presente estudo, bem como nas demais espécies brasileiras descritas na literatura, com exceção de alguns representantes de Myrceugenia (Marchiori, 1988; Santos \& Marchiori, 2009). O diâmetro de poros (81-103 $\mu \mathrm{m})$ e a altura dos raios $(520 \mu \mathrm{m})$, referidos por Paula et al. (2000), são significativamente maiores do que o observado em Siphoneugena reitzii $(36$ e $<200 \mu \mathrm{m}$, respectivamente); a freqüência de poros (13-18 $\mathrm{mm}^{2}$ ) e de raios (5-10/mm), por outro lado, são menores do que o encontrado no presente estudo $\left(131 / \mathrm{mm}^{2}\right.$ e $\left.22 / \mathrm{mm}\right)$.

Sob o ponto de vista taxonômico, salientamse, em relação a outras Myrtoídeas nativas no Estado, a altura das séries de parênquima axial e a altura relativa das margens unisseriadas dos raios. Para a maioria das espécies são referidas séries parenquimáticas com 4 ou mais células e margens unisseriadas mais altas do que o corpo central, diferentemente da espécie em estudo. Outros detalhes anatômicos, como a ausência de espessamentos espiralados, de séries cristalíferas e de pontoações raio-vasculares grandes e horizontais, podem, igualmente, ter utilidade para separar o material em estudo de outras espécies nativas, tais como: Blepharocalyx salicifolius, Campomanesia guazumaefolia, Eugenia involucrata, Feijoa sellowiana, Myrceugenia myrtoides, Myrceugenia glaucescens e Myrrhinium loranthoides.

\section{REFERÊNCIAS BIBLIOGRÁFICAS}

DENARDI, L.; MARCHIORI, J. N. C. Anatomia do lenho da murta, Blepharocalyx salicifolius $(\mathrm{H}$. B. K.) Berg. Ciência Florestal, Santa Maria, v. 15, n. 3, p. 267-274, 2005.

DUJARDIN, E. P. Eine neue Holz-Zellulosenfaerbung. Mikrokosmos, n. 53, p. 94, 1964.

IAWA COMMITTEE. IAWA list of microscopic features for hardwood identification. IAWA Bulletin, v. 10, n. 3, p. 218-359, 1989.

KRAUS, J.E.; ARDUIN, M. Manual básico de métodos em morfologia vegetal. Rio de Janeiro: EDUR, 1997. 198 p.

LEGRAND, D.; KLEIN, R. M. Mirtáceas. Flora Ilustrada Catarinense. Itajaí: Herbário Barbosa Rodrigues, 1977. p. 648-657.

MARCHIORI, J. N. C. Estudo anatômico do xilema secundário de algumas espécies dos gêneros Acacia e Mimosa, nativas no Estado do Rio Grande do Sul. 1980. 186f. Dissertação (Mestrado em Engenharia Florestal) - Universidade Federal do Paraná, Curitiba, 1980. 
MARCHIORI, J. N. C. Anatomia descritiva da madeira do murtilho Myrrhinium loranthoides (Hook. \& Arn.) Burret (Myrtaceae). Revista do Centro de Ciências Rurais, Santa Maria, v. 14, n. 1, p. 43-50, 1984a.

MARCHIORI, J. N. C. Anatomia da madeira de Eugenia involucrata DC. (Myrtaceae). Ciência e Natura, Santa Maria, v. 6, p. 127-136, 1984b.

MARCHIORI, J. N. C. Anatomia descritiva do lenho de Feijoa sellowiana Berg. Ciência e Natura, Santa Maria, v. 6, p. 117-125, 1984c.

MARCHIORI, J. N. C. Anatomia descritiva da madeira de Myrceugenia myrtoides Berg. Ciência e Natura, Santa Maria, v. 9, p. 113-120, 1987.

MARCHIORI, J. N. C. Estudo anatômico da madeira de Myrceugenia glaucescens (Camb.) Legr. \& Kaus. Ciência e Natura, Santa Maria, v. 10, p. 105-113, 1988.

MARCHIORI, J. N. C. Estudo anatômico da madeira de sete-capotes, Campomanesia guazumifolia (Camb.) Berg. (Myrtaceae). Ciência Rural, Santa Maria, v. 28, n. 1, p. 47-51, 1998.

MARCHIORI, J. N. C.; MUÑIZ, G. I. B. Estudo anatômico da madeira de Myrciaria tenella (DC.) Berg. Ciência e Natura, Santa Maria, v. 9, p. 87-95, 1987.

MARCHIORI, J. N. C; BRUM, E. T. Anatomia da madeira do guamirim-facho, Calyptranthes concinna DC. (Myrtaceae). Ciência Rural, Santa Maria, v. 27, n. 2, p. 217-222, 1997.

MARCHIORI, J. N. C.; SOBRAL, M. Dendrologia das Angiospermas: Myrtales. Santa Maria: Editora da UFSM, 1997. 304 p.
METCALFE, C. R.; CHALK, L. Anatomy of the Dicotyledons. Oxford: Clarendon Press, 1972. $1500 \mathrm{p}$.

PAULA, J. E de; JUNIOR, F. G. S.; SILVA, A. P. P. Caracterização anatômica de madeiras nativas de matas ciliares do centro-oeste brasileiro. Scientia Forestalis, v. 58, p. 73-89, 2000.

PROENÇA, C. A revision of Siphoneugena Berg. Edinburgh Journal of Botany, v. 47, p. 239-271, 1990.

RECORD, S. J.; HESS R. W. Timbers of the New World. New Haven: Yale University Press, 1949. $640 \mathrm{p}$.

SANTOS, S. R.; MARCHIORI, J, N, C. Anatomia do xilema secundário de Myrceugenia euosma (O. Berg) D. Legrand. Balduinia, n. 16, p. 2429, 2009.

SOBRAL, M. A família Myrtaceae no Rio Grande do Sul. São Leopoldo: Editora Unisinos, 2003. p. 64-65.

SOBRAL, M. Siphoneugena delicata (Myrtaceae), a new species from the montane atlantic forests of southeastern Brazil. Novon, v. 16, p. 530-532, 2006.

SOFFIATTI, P.; ALFONSO, V. A. Estudo anatômico comparativo do lenho e da casca de duas espécies de Eugenia L. (Myrtaceae). Revista Brasileira de Botânica, São Paulo, v. 22, n. 2, p. 175184, 1999.

VLIET, G. J. C. VAN; BAAS, P. Wood anatomy and classification of the Myrtales. Annals of the Missouri Botanical Garden, n. 71, p. 783-800, 1984. 